\title{
OPTIMAL INVESTMENT AND FINANCE IN A DYNAMIC MODEL OF THE FIRM
}

\author{
Eduardo Zelaya de la Parra* \\ Centro de Alta Dirección en Ingeniería Tecnológica, Universidad Anáhuac
}

(Received 15 November 2002, accepted 23 April 2003)

\begin{abstract}
Within the context of dynamic policies of the firm, an optimal control problem is formulated to find the investment and borrowing policies that maximize dividend payments. It is assumed that the firm's income per unit of debt increases with the capital/debt ratio at diminishing rates and the investment is financed through retained earnings and external borrowings. The interest rate on debt is defined as an increasing function of the debt/equity ratio, while the cost of investment per unit of debt is assumed to be convex. Also, the cost of increasing or decreasing the debt level is a convex function of the rate of borrowing per unit of debt. It is shown in this paper that, for such a firm, the optimal debt/equity ratio and the corresponding optimal trajectories for the investment and borrowing rates can be uniquely determined through out various initial conditions.
\end{abstract}

\section{Resumen}

Dentro de un contexto donde la firma determina sus políticas dinámicas, se formula un problema de control óptimo para encontrar las políticas de préstamo e inversión que maximizen el pago de dividendos. Se supone que el ingreso por unidad de deuda de una empresa aumenta cuando la razón capital/deuda disminuye las tasas y la inversion es financiada con ganancias retenidas y préstamos del exterior. La tasa de interés sobre la deuda se define como una función creciente de la razón deuda/acciones, mientras se supone que el costo de inversión por unidad de deuda es una función convexa. También, el costo de incrementar o disminuir el nivel de deuda es una función convexa de la tasa de interes a la que se pide prestado por unidad de deuda. En este trabajo se demuestra que, para cada empresa, la razón óptima de deuda/acciones y las trayectorias optimas correspondientes a la inversión y los préstamos, pueden ser determinadas mediante diferentes condiciones iniciales.

JEL classification: D21, E22, G31

Keywords: Firm behavior, Capital, Investment policy

* Centro de Alta Dirección en Ingeniería y Tecnología, Universidad Anáhuac. Av. Lomas Anáhuac s/n. Lomas Anáhuac, C.P. 52760, México, D. F., Telephone: +52(55)53288060, E-mail: ezelaya@anahuac.mx

The author is very grateful to the anonymous referees for their comments. 
subject to

$$
\begin{gathered}
\mathrm{d}(K / D) / \mathrm{d} t=(I / D)-(K / D)(B / D), \\
I / D \in[0, \infty) ; \quad B / D \in \mathbb{R} ;\left.\quad(K / D)\right|_{0}>0,\left.\quad(K / D)\right|_{\infty}=\text { free. }
\end{gathered}
$$

\section{Analysis of the Optimal Policies}

The current value Hamiltonian is

$$
\begin{aligned}
H & =\Pi(K / D)-C(I / D)-\rho-\frac{q}{(K / D)-1}+(B / D)-F(B / D) \\
& +\lambda[I / D-(K / D)(B / D)] .
\end{aligned}
$$

The optimality conditions are defined by

$$
\begin{gathered}
\frac{\partial H}{\partial(I / D)}=-C_{I / D}+\lambda \leq 0, \quad(I / D) \geq 0, \quad(I / D) \frac{\partial H}{\partial(I / D)}=0, \\
\frac{\partial H}{\partial(B / D)}=1-\lambda(K / D)-F_{B / D}=0, \\
\dot{\lambda}=\rho \lambda-\Pi^{\prime}-\frac{q}{((K / D)-1)^{2}}+\lambda(B / D) .
\end{gathered}
$$

The non-negativity condition on $(I / D)$, and the conditions on $(B / D)$ imply the existence of six different candidate paths.

\subsection{The Candidate Paths}

Path $1: I / D>0, B / D<0$.

From (9), we can see that $\mathrm{d}(K / D) / \mathrm{d} t>0$ along this path. From (12),

$$
H^{\prime}(I / D)=0, \quad H^{\prime \prime}(I / D)=-C^{\prime \prime}<0,
$$

and from (13),

$$
H^{\prime}(B / D)=0, \quad H^{\prime \prime}(B / D)=-F^{\prime \prime}(B / D)<0,
$$

which means that the Hamiltonian is maximized by unique values of $(I / D)$, and $(B / D) .(I / D)>0$ implies $\lambda=C^{\prime}>0$, and $\mathrm{d} \lambda / \mathrm{d}(I / D)=C^{\prime \prime}>0$. Since $\lambda$ is a monotonically increasing function of $(I / D)$, we can define $\Psi$ as an inverse function of $C^{\prime}$, that is $\Psi=C^{\prime-1}$, and $(I / D)=\Psi(\lambda), \Psi^{\prime}>0 .(B / D)<0$ implies that $(K / D)>(1 / \lambda)$.

Path 2: $I / D>0, B / D>0$.

The characteristics of this path are similar to those of path 1 , except that the slope of $(K / D)$ depends on the relative values of $(I / D)$, and the product $(K / D)(B / D)$. Because of this peculiarity, path 2 has two subcases. Path 2a has $\mathrm{d}(K / D) / \mathrm{d} t>0$, and $\mathrm{d} \lambda / \mathrm{d} t<0$, and path $2 \mathrm{~b}$ has $\mathrm{d}(K / D) / \mathrm{d} t<0$, and $\mathrm{d} \lambda / \mathrm{d} t>0$ (see the appendix). 
As in the previous case, the Hamiltonian is maximized by unique values of $(I / D)$, and $(B / D) .(I / D)=\Psi(\lambda)$, and $(K / D)<(1 / \lambda)$.

Path 3: $I / D>0, B / D=0$.

From (9), we see that $\mathrm{d}(K / D) / \mathrm{d} t=(I / D)>0$. We also know that $(K / D)=(1 / \lambda)$, and therefore $\dot{\lambda}<0$. The optimal trajectory along this path is $(I / D)=\Psi(\lambda)$.

Paths $1,2 \mathrm{a}$, and 3 are graphically depicted in figure 1 .

Figure 1. Trajectory of $(K / D)$ along paths $1,2 a$, and 3.

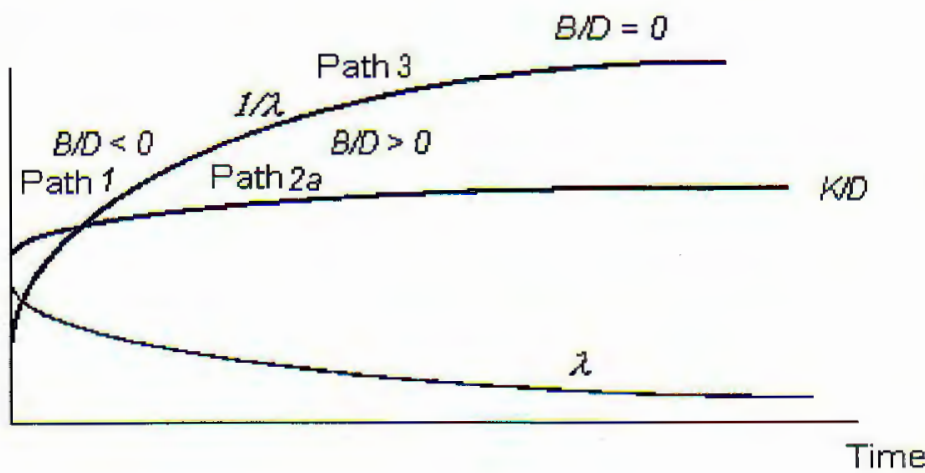

Path 4: $I / D=0, B / D<0$.

From (12), $\lambda \leq C^{\prime}$. On the other hand, from (13) we obtain

$$
\lambda=\frac{1-F^{\prime}(B / D)}{(K / D)}
$$

where by definition $F^{\prime}(B / D)<0$. Therefore, $0<\lambda \leq C^{\prime}$. Also from (9), $\mathrm{d}(K / D) / \mathrm{d} t>0$.

Path 5: $I / D=0, B / D>0$.

$$
\lambda<C^{\prime},(K / D)<(1 / \lambda) \text {, and } \mathrm{d}(K / D) / \mathrm{d} t<0 .
$$

Path 6: $I / D=0, B / D=0$.

$\lambda<C^{\prime},(K / D)=(1 / \lambda)$, and therefore $\mathrm{d}(K / D) / \mathrm{d} t=\dot{\lambda}=0$. 
of the slope of $(B / D)$ or $\lambda$. From (16), it is clear that a negative $\mathrm{d}(B / D) / \mathrm{d} t$ would make $\mathrm{d} \lambda / \mathrm{d} t$ positive. This possibility is consistent with the pattern observed on path $2 \mathrm{~b}$.

\section{Results and Conclusions}

Sequence $1 \rightarrow 3 \rightarrow 2$ a (figure 3 ) corresponds to the case where the initial value of $(K / D)$ is less than its optimal equilibrium level.

$$
\left.(K / D)\right|_{0}<(K / D)^{*}
$$

Either a low $K$ or a high $D$, or both, may cause a small initial value of $(K / D)$. To make $(K / D)$ grow at its maximum value on path 1 , high initial rates of investment, and debt repayment are necessary.

Figure 3. Optimal Solution in the Case of an Initial $(K / D)$ below the Optimal Equilibrium Level.

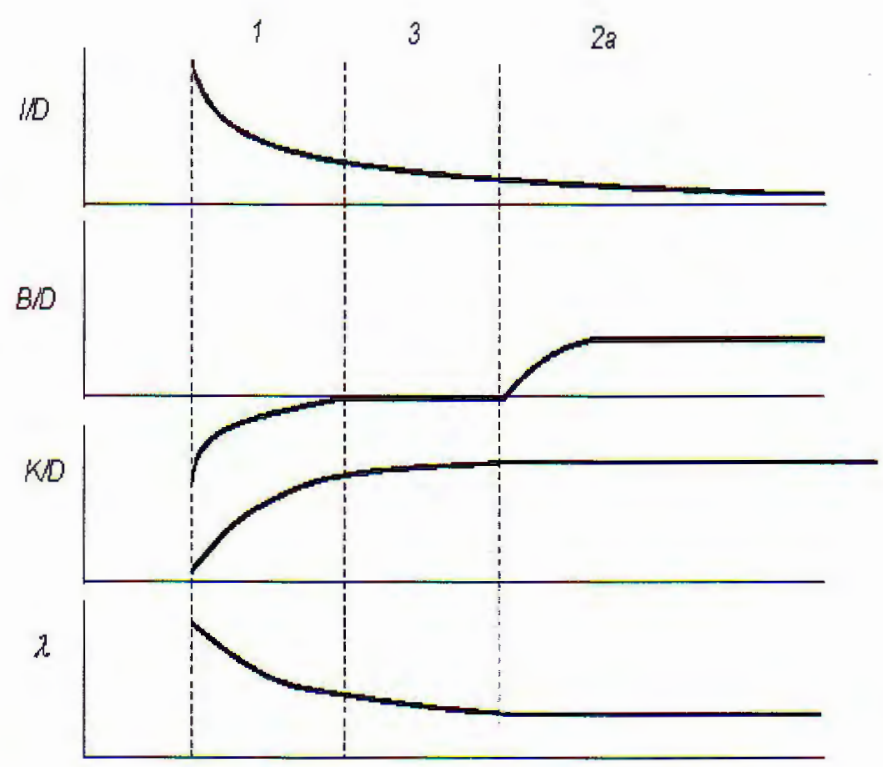

Since the equilibrium level of debt is positive, $(B / D)$ is approaches first to zero, and remains at this value along path 3 , whereas $(I / D)$ decreases. After, $(B / D)$ grows along path $2 \mathrm{a}$, and approaches the positive value (borrowing) necessary to maintain the optimal equilibrium level of $(K / D)$. The investment rate steadily decreases to its equilibrium value.

From the steady state analysis, which appears in the appendix, the equilibrium value of $(K / D)$ is $(I / D)$. Substituting this result in $(7)$, and rearranging, we obtain the optimal debt/equity ratio

$$
D / E=\frac{D}{I-D},
$$


where the investment rate must always be greater than the borrowing rate.

Sequence $5 \rightarrow 2 b$ (figure 4 ) applies to an initial $(K / D)$ greater than the optimal equilibrium level. Therefore, we would expect that $(K / D)$ decreasing at its maximum rate to approach the equilibrium level as soon as possible. This is consistent with path 5 , which has a zero valued $(I / D)$, and a large initial $(B / D)$. We shall not delve more deeply on this case, since our results are somewhat speculative, although the conclusions about the optimal debt/equity ratio obtained for the sequence $1 \rightarrow 3 \rightarrow 2 a$, also apply to this case.

Figure 4. Optimal Solution in the Case of an Initial $(K / D)$ above the Optimal Equilibrium Level.

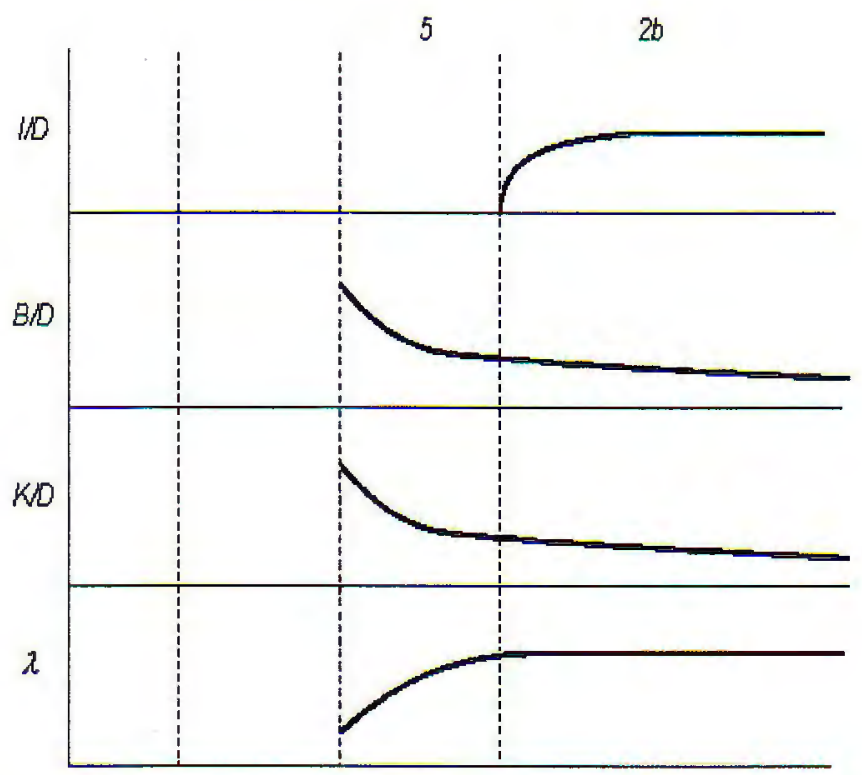

It has been shown that for a firm defined under a few feasible assumptions, the optimal debt/equity ratio, and the corresponding optimal trajectories for the investment, and borrowing rates that maximize dividend payment can be uniquely determined for various initial conditions.

\section{Appendix: Intertemporal Equilibrium along Path 2}

If $\mathbf{K}=(K / D)$ and $\dot{\mathbf{K}}=\mathrm{d}(K / D) / \mathrm{d} t$, we then use the differential-cquation system of the model $(9)$ and $(14)$, with $(I / D)>0$ and $(B / D)>0$ to form the Jacobian Matrix,

$$
\mathbf{J}=\left[\begin{array}{cc}
\partial \dot{\mathbf{K}} / \partial \mathbf{K} & \partial \dot{\mathbf{K}} / \partial \lambda \\
\partial \dot{\lambda} / \partial \mathbf{K} & \partial \dot{\lambda} / \partial \lambda
\end{array}\right]
$$


and evaluate the determinant of this matrix $\mathbf{J}$ at the steady-state point $\mathrm{E}$,

$$
\mathbf{J}_{\mathbf{E}}=\left[\begin{array}{cc}
-(B / D) & 0 \\
-\Pi_{K K}+2 q /(K-1)^{3} & \rho+(B / D)
\end{array}\right]
$$

The information that we need about the characteristic roots to confirm the saddle point is conveyed by

$$
\left|\mathbf{J}_{\mathbf{E}}\right|=-B / D(\rho+B / D)<0 .
$$

This implies that the two roots have opposite signs, which establishes the steady-state to be locally a saddle point. Additional qualitative information can be obtained from the phase diagram (figure 5 ). On the basis of equations (9) and (14)

$$
\begin{aligned}
& \mathrm{d}(K / D) / \mathrm{d} t=(I / D)-(K / D)(B / D)=0, \\
& \dot{\lambda}=\rho \lambda-\Pi^{\prime}-\frac{q}{(K / D-1)^{2}}+\lambda(B / D)=0 .
\end{aligned}
$$

From (A.1) and (A.2), we have

$$
(K / D)^{*}=I^{*} / B^{*}, \text { and } \lambda^{*}=\frac{\Pi^{\prime}+q /\left[(K / D)^{*}-1\right]^{2}}{\rho+(B / D)^{*}}
$$

where the upper index ${ }^{*}$ denotes the optimal values of the variables.

Figure 5. Phase Diagram.

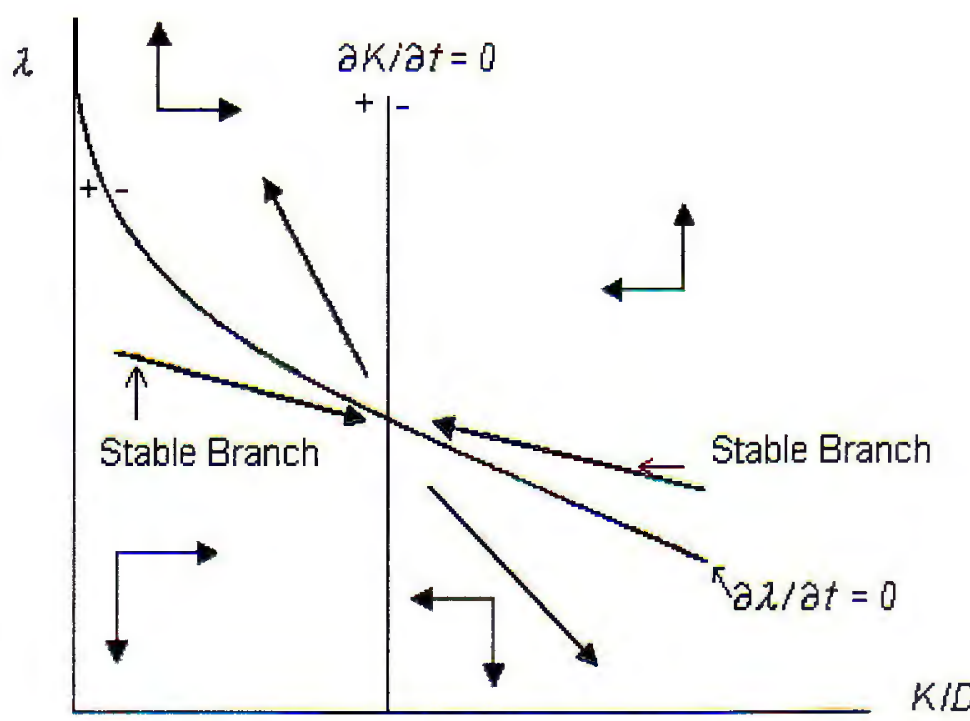


It can be observed that the two stable branches are characterized by

$$
\frac{\mathrm{d}(K / D)}{\mathrm{d} t}>0, \text { and } \mathrm{d} \lambda / \mathrm{d} t<0(\text { path } 2 \mathrm{a})
$$

and

$$
\frac{\mathrm{d}(K / D)}{\mathrm{d} t}<0 \text {, and } \mathrm{d} \lambda / \mathrm{d} t>0(\text { path } 2 \mathrm{~b}) \text {. }
$$

\section{References}

Ghosh, D. (1992). Optimum Capital Structure Redefined. The Financial Review, 27(3), pp. 411-429.

Bohl, A., and F. H. Murphy (1991). The Effect of the Mix of Equity and Debt on the Selection of Projects. The Engineering Economist, 1, pp. 61-74.

Kort, P. M. (1990). A Dynamic Net Present Value Rule in a Financial Adjustment Cost Model. Optimal Control Applications \& Methods, 11, pp. 277-282.

Jørgensen, S., and P. M. Kort (1997). Optimal Investment and Finance in Renewable Resource Harvesting. Journal of Economic Dynamics and Control, 21, pp. 603-630.

Van Hilten, O., P. M. Kort, and P. Van Loon (1993). Dynamic Policies of the Firm: An Optimal Control Approach. Springer-Verlag, Berlin. 